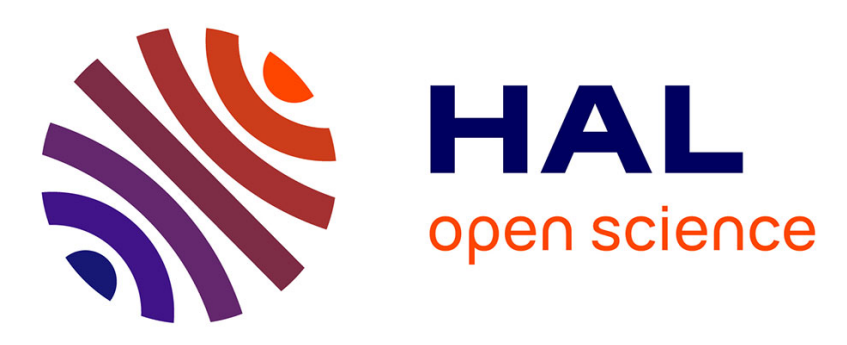

\title{
Influence of relative humidity on Delayed Ettringite Formation
}

Mohamad Al Shamaa, Stéphane Lavaud, Loïc Divet, Georges Nahas, Jean Michel Torrenti

\section{- To cite this version:}

Mohamad Al Shamaa, Stéphane Lavaud, Loïc Divet, Georges Nahas, Jean Michel Torrenti. Influence of relative humidity on Delayed Ettringite Formation. Cement and Concrete Composites, 2015, 58, pp.14-22. 10.1016/j.cemconcomp.2014.12.013 . hal-01214456

\section{HAL Id: hal-01214456 https://hal.science/hal-01214456}

Submitted on 14 Oct 2015

HAL is a multi-disciplinary open access archive for the deposit and dissemination of scientific research documents, whether they are published or not. The documents may come from teaching and research institutions in France or abroad, or from public or private research centers.
L'archive ouverte pluridisciplinaire HAL, est destinée au dépôt et à la diffusion de documents scientifiques de niveau recherche, publiés ou non, émanant des établissements d'enseignement et de recherche français ou étrangers, des laboratoires publics ou privés. 
Title of the paper:

\section{Influence of relative humidity on Delayed Ettringite Formation}

Authors:

Mohamad Al Shamaa ${ }^{1,2}$, Stéphane Lavaud ${ }^{1}$, Loic Divet ${ }^{1}$, Georges Nahas ${ }^{2}$, Jean Michel Torrenti ${ }^{1}$ Affiliations:

1) Université Paris-Est, IFSTTAR, France

2) Institut de Radioprotection et de Sûretée Nucléaire (IRSN), 31 avenue de la Division Leclerc, 92260 Fontenay-aux-Roses, France

Corresponding author :

Jean Michel Torrenti

Tel : +33181668440

Fax : +33181668990

jean-michel.torrenti@ifsttar.fr 


\title{
Influence of relative humidity on Delayed Ettringite Formation
}

\begin{abstract}
This experimental study aims to determine the effect of relative humidity on concrete expansion due to delayed ettringite formation (DEF), which still remains imperfectly known. Test methods were designed to trigger reaction in concrete specimens and determine how ambient RH affects expansion of the specimens. Saturated salts solutions were used to achieve distinct ambient RH conditions within containers. Also, chemical analysis was performed to determine and quantify the fractions of alkalis leaching out of the pore solutions of concretes. Results showed that the critical ambient RH value that corresponds to significant suppression of DEF could be greatly dependent on the alkalis fractions leached out. Finally, the consequences of swelling due to DEF on the concrete properties are assessed. After swelling, both of gas permeability and porosity was increased significantly and dynamic modulus was reduced by about $45 \%$.
\end{abstract}

Keywords: Concrete, Delayed Ettringite Formation, Humidity, Alkalis, Permeability, Mechanical Properties

\section{Introduction}

The exposure of concrete in a very moist environment is one of the main conditions for the development of delayed ettringite formation (DEF). The parts of a concrete structure affected 
by this pathology are mainly those in contact with water (submerged area, tidal zone) or subjected to inflows of water (defect in sealing) or those exposed to high humidity [1-4]. The potential for expansion due to DEF is directly related to relative humidity inside concrete, which is greatly influenced by ambient relative humidity. In general, the amplitude and the rate of swelling due to DEF increase with increasing surrounding humidity of materials [5-9]. Thus, because expansion by DEF is driven by the availability of water, the reaction could be halted if the $\mathrm{RH}$, and thus availability of water, inside concrete becomes low enough. Water represents an essential agent for the reaction of formation of ettringite because one molecule of ettringite contains 32 molecules of water. It also promotes the mobility of other agents and is responsible for leaching of alkalis out of the pore solution which induces a decrease in $\mathrm{pH}$ and thus favors the precipitation of ettringite. Indeed, the decrease of $\mathrm{pH}$ accelerates the release of sulfate ions adsorbed on the C-S-H at early age [10-11].

The effects of concrete composition and curing conditions on the expansion due to DEF have been widely studied [12-22], but very little studies have been performed on the influence of relative humidity of the materials storage environment. Graf [8] established that there is a $\mathrm{RH}$ threshold of $92 \%$ for the appearance of expansion by DEF.

Therefore, the present study is an attempt to clarify the influence of relative humidity on expansion associated with DEF in concrete. In addition to storage under water and at RH of $100 \%$, saturated solutions of different salts were used to achieve various moist exposures for concrete specimens with different levels of RH. Testing performed included the control of the moisture environments, monitoring of concrete swelling and weight variations, and alkalis leaching analysis. Microstructure characterization of concretes was also done by scanning electron microscopy (SEM). The follow up of dynamic modulus, gas permeability and porosity are also presented in order to assess the consequences of swelling on concrete properties. 


\section{Experiments}

\subsection{Materials, specimens curing and storage}

Concrete composition used in this study is given in Table 1. It is made with siliceous aggregates and Portland cement CEM I 52.5N. The chemical and mineralogical compositions of the cement are given in Tables 2 and 3. This cement was selected because of its large sulfate and alkali contents which are major factors for DEF [30]. The concrete mix was designed for its known expansive behavior when used in concretes heat-treated and immersed in water after casting [31]. Tests were performed on cylinders with $11 \mathrm{~cm}$ in diameter and 22 $\mathrm{cm}$ in height.

After casting, the concrete specimens were tightly covered to prevent them from evaporation of water and then cured in their molds according to the heat treatment presented in Figure 1. The specimens were placed in a drying oven equipped with a temperature/humidity controller. The treatment is divided into four steps. Firstly, the samples were procured at $20^{\circ} \mathrm{C}$ for 2 hours. Then, the temperature was increased at a rate of $2.5^{\circ} \mathrm{C} / \mathrm{h}$ to $80^{\circ} \mathrm{C}$. The temperature was maintained at $80^{\circ} \mathrm{C}$ for 3 days. Finally, the temperature was decreased at a rate of $-1^{\circ} \mathrm{C} / \mathrm{h}$ to $20^{\circ} \mathrm{C}$. So the total duration of the heat treatment is 7 days. This treatment is representative of the temperature cycle of a massive concrete structure due to the heat of hydration of cement (see [28] for an example in the case of the raft foundation of a nuclear power plant).

After the heat treatment, the specimens were demoulded and then stored at $20^{\circ} \mathrm{C}$ in different conditions: in tap water, at $\mathrm{RH}$ of $100 \%$, and in four controlled $\mathrm{RH}$ environments with 
different levels of RH. Our initial purpose was to ensure four levels of RH in the range from about $90 \%$ to $100 \%$.

For the immersion, the specimens were stored in tap water, each one in a container whose dimensions (internal diameter $=13 \mathrm{~cm}$, height $=23 \mathrm{~cm}$ ) are slightly larger than those of specimen (diameter $=11 \mathrm{~cm}$ and height $=22 \mathrm{~cm}$ ). The storage at $\mathrm{RH}$ of $100 \%$ was achieved by placing the specimens above a water level in a sealed container which consists in a cylinder made out of Plexiglas where a pump allows a circulation of water on the inner side, and thus saturates the ambient air with vapor (Figure 2) [9]. For the storage at the other RH, environments were achieved by using different saturated salts solutions. The specimens were placed above the solution in a sealed container (Figure 3). Table 4 listed the salts used for preparing the solutions. These have been chosen based on data reviewed by Young [23] and work referred by him [24], and after a preliminary study which was carried out to estimate the value of RH assured by each solution and to assess its evolution over time after storage of porous materials. Each of the values shown in table 4 represents an approximate theoretical RH level achieved by allowing equilibrium between vapor pressure of the solution and the air above. But the storage of porous materials in air has effects on the exchange of moisture with the surrounding air. In our study, monitoring of RH and temperature was achieved by using humidity/temperature probes with an accuracy reported by the manufacturer equal to $\pm 0.8 \%$. After the storage of the specimens, RH values were close to constant and were approximately equal to $91 \%, 94 \%, 96 \%$ and $98 \%$ (Figure 4). The temperature of the storage room was carefully controlled to be maintained close to $20^{\circ} \mathrm{C}$ during all the period of storage, because the humidity assured by some of the solutions is very much influenced by variations of the temperature around $20^{\circ} \mathrm{C}$. However, a slight increase was observed for measurements at RH of $98 \%$. This was expected because of the long stay of the humidity probe at moisture close of saturation. In addition, a slight decrease is observed in the case of $91 \% \mathrm{RH}$ for all the storage 
duration. Smaller decreases were also observed in the case of $94 \%$ and $96 \% \mathrm{RH}$, after a recalibration of the probes (at the age of 340 days). That is why it is essential to confront our data to the mass changes.

Finally, to assess the effects of a belated humidification on the swelling due to DEF, specimens stored at RH of $91 \%$ were immersed in water at the age of 334 days. On the other hand, some of concrete specimens initially immersed in water were protected, each one by three coating of an aluminium self-adhesive tape, at the age of 90 days and were kept at $100 \%$ RH. This date was chosen during the acceleration of swelling to evaluate the effect of stopping the external water supply on the evolution of the expansion.

The following nomenclature will be used to facilitate discussion of the results:

- Im for concretes that have been immersed continuously in water;

- RH94, RH96, RH98 and RH100 for concretes that have been stored respectively at $94 \%$, $96 \%, 98 \%$ and $100 \%$ RH;

- RH91-Im for concretes that have been stored at $91 \%$ RH and then immersed in water from the age of 334 days;

- Im-Is for concretes that have been immersed in water and then isolated and kept under sealing at $100 \%$ RH from the age of 90 days.

\subsection{Measurements}

Axial expansion of concrete specimens was monitored with a digital extensometer by measuring the length change using steel studs glued on three locations placed at 120 degrees from each other around the diameter. These studs are aligned per pair along the height of the specimen. The initial distance between two studs is $10 \mathrm{~cm}$, and the variation of this distance 
over time assesses the expansion of the specimen. The water uptake was also monitored by weighting the specimens. Additionally, a follow-up of the dynamic modulus was carried out by measuring resonance frequency using a prototype whose procedure consists of exciting the concrete specimen by an impact at the center of one of its bases. The resonance frequency is obtained by the measurement of the first longitudinal oscillation frequency and is linked to the dynamic modulus of the material by the following equation [16]:

$$
f_{\text {longi }}=\frac{1}{2 L} \sqrt{\frac{E_{d y n}}{\rho}}
$$

in which $f_{\text {longi }}$ is the longitudinal self-oscillation frequency $\left[\mathrm{s}^{-1}\right], L$ is the height of the specimen [m], $E_{d y n}$ is the dynamic longitudinal elastic modulus [Pa] and $\rho$ is the density of the specimen $\left[\mathrm{kg} / \mathrm{m}^{3}\right]$.

For each storage condition, average of each of the previous measurements was computed from three different specimens.

Additionally, the $\mathrm{K}^{+}$and the $\mathrm{Na}^{+}$concentrations were monitored by inductively coupled plasma spectrometry for concretes Im and RH100 at the age of 590 days, and for concrete RH98 at the age of 520 days. The fractions of each cation leached out were then estimated from the alkali contents of the cement, the cement content and the weights of the concrete specimens.

Also, scanning electron microscope (SEM) observations were performed on polished sections at the age of 460 days for concretes RH100 and Im, and at the age of 400 days for concretes RH94, RH96 and RH98.

Finally, monitoring of porosity and gas permeability was performed. Five measurements were done on concretes Im and RH100: at the age of 28 days, during the initialization of swelling, 
during the intermediate swelling, after the strong swelling and during the asymptotic phase (Figure 5). Two measurements (at the ages of 28 and 245 days) were also carried out on concretes RH91-Im, RH94, RH96 and RH98.

The porosity was obtained by weighing difference between the specimen that have undergone imbibition in water at a pressure of $22 \mathrm{mbar}$ at $20^{\circ} \mathrm{C}$ for 48 hours and the same specimen dried in an oven at $105^{\circ} \mathrm{C}[25]$.

For the measurement of gas permeability, intrinsic permeability was measured using a Cembureau constant head permeameter with nitrogen as the neutral percolating gas. Each specimen was tested at four differential pressures. For each pressure, the apparent coefficient of permeability $k_{A}\left(\mathrm{~m}^{2}\right)$ is calculated from the following relationship [26]:

$k_{A}=\frac{Q}{A} \frac{2 \mu L P_{a t m}}{\left(P_{i}^{2}-P_{a t m}^{2}\right)}$

in which $L$ is the thickness of the sample (m), $A$ is the cross-sectional area $\left(\mathrm{m}^{2}\right), Q$ is the measured gas flow $\left(\mathrm{m}^{3} / \mathrm{s}\right), \mu$ is the coefficient of viscosity $\left(1.76 \times 10^{-5} \mathrm{~Pa}\right.$ for nitrogen gas at $\left.20^{\circ} \mathrm{C}\right), P_{i}$ is the inlet applied pressure $(\mathrm{Pa})$ and $P_{\text {atm }}$ is the atmospheric pressure $(\mathrm{Pa})$.

Using the Klinkenberg approach, the intrinsic permeability $k_{V}\left(\mathrm{~m}^{2}\right)$ relative to viscous flow can be determined by the following relationship:

$$
k_{A}=k_{V}\left(1+\frac{\beta}{P_{m}}\right)
$$

in which $P_{m}=\left(P_{i}+P_{a t m}\right) / 2$ and $\beta$ is the Klinkenberg coefficient $(\mathrm{Pa})$. The determination of $k_{v}$ and $\beta$ consists in measuring $k_{A}$ at different pressures $P_{i}$ and in plotting it against the inverse of the mean pressure $1 / P_{m}[27]$. 


\section{Results}

\subsection{Mass uptake and swelling}

Figure 6 shows the expansion curves obtained for different concrete storage conditions. The results clearly show that, in general, the relative humidity has a strong effect on the expansion due to DEF. An identical expansion behavior is observed for concretes Im and HR100 which present high levels of swelling with the same rate during all the period of storage. Expansion level for these concretes reaches about $1.30 \%$ at around 1000 days. On the other hand, none of the concretes that have been stored at $96 \%$ and $94 \%$ RH present significant swelling after 1250 days of storage. Figure 7 permits with an extended scale to observe more clearly the expansion evolutions of these concretes. The measured expansion at 1250 days for these concretes was less than $0.08 \%$. For concrete HR98, we observe an acceleration of swelling at around 600 days, and the expansion level at 1250 days was equal to $0.32 \%$.

In parallel, Figure 8 shows weight variations for all concrete samples. Specimens immersed in water and stored at $100 \%$ and $98 \% \mathrm{RH}$ start to gain weight right at the beginning, while specimens stored at $96 \%$ and $94 \% \mathrm{RH}$ start by decreasing their weight, and later start gaining weight at different rates. The magnitude and the rate of the mass uptakes are similar in both concretes Im and RH100. Concretes stored at $96 \% \mathrm{RH}$ return to their initial weight after around 350 days, while concretes stored at 94\% RH reach their initial weight after 850 days of storage. An acceleration of the weight gain of concrete RH98 is also noted at around 500 days, and is in accordance with its expansion behavior, which also presents an increase of its rate at this moment. 
The absence of significant swelling in concretes stored at $98 \% \mathrm{RH}$ and below is due to a lack of significant external water supply. Since water is an essential agent, ettringite formation potential might have been exhausted and expansion not triggered. In addition, the low availability of water makes leaching of alkalis significantly slowed and thus the internal $\mathrm{pH}$ of concrete high. Under these conditions, release of sulfate adsorbed on the C-S-H is considerably slowed [10-11], the sulfates are less movable and the rate of expansion is thus slowed.

On the other hand, for concrete RH91-Im, we observe at the moment of the belated immersion, a brutal weight gain which reaches a level higher than that of the case of early immersion (3.36\% at 950 days). This was accompanied by a significant acceleration of expansion. It also appears that the rate of swelling and the latency period are identical to those observed in the case of early humidification. This shows that the exposure of concrete to an insufficient RH for the occurrence of DEF does not lead to a definitive suppression of swelling. The expansion potential was just latent.

In addition, we note a significant reduction in the rate of swelling in the concrete Im-Is after the application of the coating. However, the external supply of water has not been prevented despite all precautions, because aluminum was unable to resist the water for a long time. Mass gain seems to reach a level slightly less than that achieved by concretes Im and RH100. This was accompanied by a re-acceleration of the expansion which reaches very high values $(0.9 \%$ at 530 days).

\subsection{Hydrous behavior and leaching of alkalis}


Expansions versus weight variations for concretes Im, Im-Is, RH100, RH98 and RH91-Im are presented in Figure 9. Despite that the swelling rate of concrete Im-Is is different than that of concretes Im and RH100, we observe a similar hydrous behavior during the intense swelling for these concretes. Indeed, we note that beyond a threshold weight gain of about $0.2 \%$, expansions and mass gains are linked by an affine relationship, and curves reveal almost linear with similar slopes. In addition, after the onset of swelling for concrete RH91-Im due to a belated immersion in water, we observe a similar slope to that of concretes subjected to early humidification, and then a similar hydrous behavior. However, the hydrous behavior of concrete RH98 seems to be different. Indeed, a mass uptake of about $1 \%$ was needed to accelerate swelling for this concrete, and the rate of the curve after this acceleration seems to be smaller than that of other concretes. This means that a same quantity of water supply does not have the same effect on swelling due to DEF. It depends on the ability of this water supply to lead to an important leaching of alkalis, which promotes the precipitation of ettringite. Leaching of alkalis is happened at a much slower rate for concretes stored at $98 \% \mathrm{RH}$ than those immersed in water or stored at $100 \% \mathrm{RH}$. Figure 10 shows that about $80 \%$ of the $\mathrm{K}^{+}$ was leached out of the pores solution for concretes RH100 and Im at 590 days, but only 20\% was leached in the case of concrete RH98 at 520 days. This leads to consider that a critical level of alkalis fraction leached, and not a critical level of water gain, was required to trigger the expansion. In addition, after the onset of the swellings, the induced microcracks seem to promote water ingress, further alkalis leaching and thus ettringite formation.

$\mathrm{The}^{+} \mathrm{Na}^{+}$fractions leached were unable to be estimated due to the low proportion of this cation in the concrete (about $0.02 \%$ ). Thus it was difficult to compare the initial quantities to those dosed at such orders of magnitude. 


\subsection{SEM observations}

Figure 11 shows microscope observations at 460 days on polished sections of concretes Im and RH100 whose expansion was equal to $1.24 \%$. It is possible to clearly recognize pervasiveness of delayed ettringite band in the cement paste-aggregate interfaces, but also in the developed cracks in the cement paste and sometimes in the pores. Ettringite within interfaces and cracks always occupies the entire space available, and we rarely detected empty cracks. This could mean that this is the formation of ettringite which provokes the opening of the crack. In general, the ettringite makes bands which bypass aggregates and cross the cement paste as the form of veins, to then reach another aggregate nearby. On the other hand, Figures 12 illustrates images derived from observations at 400 days on polished sections of concretes RH94, RH96 and RH98 whose expansion was less than $0.02 \%$. They reveal the almost total absence of ettringite. However, very few traces of ettringite were detected, such as nodules deposits in the cement paste (Figure 12-c) and do not seem to be symptomatic of swelling. In addition, there is no trace of microcracks observable in the paste. These concretes seem to be compact, paste-aggregate interfaces cohesive (Figure 12-a), and cement paste healthy (Figure 12-b).

\subsection{Dynamic modulus}

Dynamic modulus variations are given in Figure 13. A slow and progressive increase with time is noted in concretes stored at $96 \%$ and $94 \% \mathrm{RH}$. This reflects a slight improvement in the mechanical properties due to a small increase in the degree of hydration. For concrete 
RH98, the increase in the modulus is followed by a decrease at around 650 days, and this is in accordance with its expansion behavior that presents an acceleration at this moment.

For concretes stored at $100 \% \mathrm{RH}$ and those immersed in water which exhibited the highest expansion of all the specimens examined, the dynamic modulus evolution shows a significant reduction from about 45 days when the inflection point of the acceleration of the expansion curve is reached. The percentage reduction from the peak value reached was almost $45 \%$, the modulus dropping to a low value of about $22 \mathrm{GPa}$ at 140 days. This reflects a damage of concrete due to development of microcracks in the cement paste after swelling by DEF. Then, when expansion starts to stabilize, a progressive improvement in dynamic modulus is observed. This could be explained by the effect of a progressive filling of previously-opened cracks by ettringite massive deposits.

Concrete RH91-Im shows initially a slow and gradual increase in modulus (similar to the case of concretes RH94, RH96 and RH98), followed by a drop reflecting a damage due to the development of belated swelling after immersion in water, and then a re-increase identical to that of concretes RH100 and Im.

These results are in agreement with those obtained by Brunetaud [16] about the fact that the sigmoid swelling induces significant decrease of dynamic modulus.

\subsection{Effect of swelling on permeability and porosity}

Results plotted on Figure 14 present the relative intrinsic permeability (permeability at a given time over initial permeability measured at 28 days) versus expansion for concretes Im and RH100. Under the action of swelling by DEF, the permeability increases very significantly with a ratio which reaches about 70 when expansion reaches $0.70 \%$. This shows its very 
strong variation with expansion and reflects the development of a connected microcracks network in the cement paste. This is in accordance with previous results obtained with another concrete and with modelling of the development of DEF using a meso-macro approach [28, 29]. Then, since the swelling from this expansion level begins to slow down, the permeability of concrete immersed in water tends to stabilize until the end of follow-up. This ratio remains almost constant or even decreases very slightly (around 62 at the last measurement). For concrete RH100, permeability increases to reach a ratio of 90 and then decreases to reach a ratio of about 63. During this phase, a possible filling of opened cracks by ettringite massive deposits could be the source of this decrease. This is in agreement with the re-increase of dynamic modulus during the phase of slowdown of swelling.

The same effect is also noticeable on the apparent permeability (Figure 15).

In parallel, the relative variation of the Klinkenberg coefficient $\beta$ ( $\beta$ at a given time over initial $\beta$ measured at 28 days) of these concretes shows a decrease of this one (Figure 16). Since it is inversely proportional to the average diameter of the pores, this decrease reveals an increase in the pore size. The total porosity also increases of about $4 \%$ when expansion reaches $1.22 \%$ (Figure 17). In addition, the evolution of $\beta$ joins the results of the permeability evolution. Indeed, there is a good correlation between changes in these two parameters: an increase in $\beta$ for concrete Im at the fourth measurement is accompanied by a decrease in permeability, and a slight decrease of $\beta$ at the last measurement is accompanied by an increase of permeability. This is also observed in the case of concrete RH100 but with opposite trends.

On the other hand, no changes were observed in the permeability and the porosity of concretes RH91-Im (before immersion), RH94, RH96 and RH98 which do not suffer from DEF. As shown in the Figures 18 and 19, permeability and porosity of these concretes remain almost constant at 245 days. 


\section{Discussion}

The results presented in this paper are not in agreement with those obtained by Graf [8] who studied the impact of relative humidity on DEF in mortars stored at RH levels between $75 \%$ and $100 \%$ after they were heated with a maximum temperature of $90^{\circ} \mathrm{C}$ for 10 hours (which is representative of the treatments used in some precast industries and which is normally less hard than our treatment). He finds that exposure to $92 \% \mathrm{RH}$ and higher provided the development of DEF (expansion of $0.9 \%$ at 700 days), and no expansion was observed in mortars stored at $90 \% \mathrm{RH}$ and below. This difference in the results could be mainly due to the fact that specimen dimensions in the study of Graf were very much smaller $(25 \mathrm{~mm} \times 25 \mathrm{~mm}$ $\times 285 \mathrm{~mm}$ ) than those of our specimens. This leads to a faster leaching of alkalis, and thus faster and more significant swelling. On the other hand, it should be also noted that in the study of Graf, there was significant differences in the expansion and mass variations between individual bars stored at the same RH. This is due to moisture gradients within the individual containers, and expansion behavior was uniform only in the case of storage under water. However, in our study, the individual mass variations (and also for expansion evolutions) of specimens show highly uniform variations in all storage conditions, as shown for example in Figure 20 in the case of concretes RH100, RH98 and RH96. This confirms that the distribution of moisture in our containers is highly uniform.

Finally, it seems that it is not correct to set a relative humidity threshold from which a DEF develops in the cementitious materials. This one depends on many factors, especially the specimen sizes which influence significantly the leaching of alkalis and thus the precipitation of ettringite and swelling rate. 


\section{Conclusions}

In this study, the influence of relative humidity on the development of DEF was tested. Using a concrete made with a cement sensitive to the formation of delayed ettringite formation and after an heat treatment at early age, specimens immersed in water and stored at $100 \% \mathrm{RH}$ presented an expansion very quickly. For those stored at $98 \% \mathrm{RH}$ expansion occurs after a long period (600 days). And below 98\% RH actually no expansion is observed. This effect is due to the combination of water availability and leaching of alkalis out of the concrete pore solution. Even though continuous weight gain was observed in the long term storage for some concretes, it was not sufficient to provide the conditions required to develop DEF-related expansion.

After about 330 days of exposure to drying conditions (at 91\% RH), subsequent exposure under water provided the occurrence of DEF with the same rate of that with an early immersion in water.

It was also observed that the concrete properties are significantly affected by DEF expansion. The gas permeability increased by a factor 70 after a swelling of $0,7 \%$, and dynamic modulus was decreased.

Other studies will be necessary to study the effects of relative humidity on DEF. Parameters that control the leaching of alkalis should be considered, such as the size of the specimens.

\section{Acknowledgements}


The authors gratefully acknowledge the IRSN (Institut de Radioprotection et de Sûreté Nucléaire) for providing the financial support for this research.

\section{References}

[1] Mielenz RC, Marusin SL, Hime WG, Jugovic ZT. Investigation of prestressed concrete railway tie distress. ACI Concr Int 1995; 17: 62-68.

[2] Lawrence BL, Myers JJ, Carrasquillo RL. Premature concrete deterioration in Texas Department of Transportation precast elements, in: B. Erlin (Ed.), Ettringite - The sometimes host of destruction. ACI SP177, 1999; pp. 141-158.

[3] Godart B, Divet L. The new French recommendations to prevent disorders due to delayed ettringite formation. $13^{\text {th }}$ International Conference on Alkali Aggregate Reaction ICAAR, Trondheim, Norway, 2008.

[4] Boenig A, Funez LM, Memberg L, Roche J, Tinkey B, Klingner RE, Fowler TJ. Structural assessment of bridges with premature concrete deterioration due to expansive reactions. ACI Struct J 2009; 106: 196-204.

[5] Odler I, Chen Y. Effect of cement composition on the expansion of heat-cured cement pastes. Cem Concr Res 1995; 25: 853-862. 
[6] Heinz D, Kalde M, Ludwig U, Ruediger I. Present state of investigation on damaging late ettringite formation (DLEF) in mortars and concretes, in: B. Erlin (Ed.), Ettringite - The sometimes host of destruction. ACI SP177, 1999; pp. 1-14.

[7] Famy C, Scrivener KL, Atkinson A, Brough AR. Influence of the storage conditions on the dimensional changes of heat-cured mortars. Cem Concr Res 2001; 31: 795-803.

[8] Graf L. Effect of relative humidity on expansion and microstructure of heat-cured mortars. RD139, Portland Cement Association. Skokie, Illinois, USA, 2007, 50 pp.

[9] Martin RP. Analyse sur structures modèles des effets mécaniques de la réaction sulfatique interne. Thèse de doctorat (PhD Thesis, in French). France, Université Paris-Est, 2010.

[10] Divet L, Randriambololona R. Delayed ettringite formation: The effect of temperature and basicity on the interaction of sulphate and C-S-H Phase. Cem Concr Res 1998; 28: $357-$ 363.

[11] Taylor HFW, Famy C, Scrivener KL. Delayed ettringite formation. Cem Concr Res 2001; 31: 683-693.

[12] Kelham S. The effect of cement composition and fineness on expansion associated with delayed ettringite formation. Cem Concr Compos 1996; 18:171-179.

[13] Fu Y, Ding J, Beaudoin JJ. Expansion of Portland cement mortar due to internal sulfate attack. Cem Concr Res 1997; 27: 1299-1306. 
[14] Grattan-Bellew PE, Beaudoin JJ, Vallée VG. Effect of aggregate particle size and composition on expansion of mortar bars due to delayed ettringite formation. Cem Concr Res 1998; 28: 1147-1156.

[15] Scrivener KL, Lewis MC. Effect of heat curing on expansion of mortars and composition of calcium silicate hydrate gel, in: B. Erlin (Ed.), Ettringite - The sometimes host of destruction, ACI SP177, 1999, pp. 93-104.

[16] Collepardi M. A state-of-the-art review on delayed ettringite attack on concrete. Cem Concr Compos 2003; 25:401-407.

[17] Tosun K. Effect of $\mathrm{SO}_{3}$ content and fineness on the rate of delayed ettringite formation in heat cured Portland cement mortars. Cem Concr Compos 2006; 28:761-72.

[18] Escadeillas G, Aubert JE, Segerer M, Prince W. Some factors affecting delayed ettringite formation in heat-cured mortars. Cem Concr Res 2007; 37: 1445-1452.

[19] Brunetaud X, Divet L, Damidot D. Impact of unrestrained delayed ettringite formationinduced expansion on concrete mechanical properties. Cem Concr Res 2008; 38: 1343-1348.

[20] Zhang Z, Olek J, Diamond S. Studies on delayed ettringite formation in early-age, heatcured mortars I. Expansion measurements, changes in dynamic modulus of elasticity and weight gains. Cem Concr Res 2002; 32: 1729-1736. 
[21] Zhang Z, Olek J, Diamond S. Studies on delayed ettringite formation in early-age, heatcured mortars II. Characteristics of cement that may be susceptible to DEF. Cem Concr Res 2002; 32: 1737-1742.

[22] Ramlochan T, Zacarias P, Thomas MDA, Hooton RD. The effect of pozzolans and slag on the expansion of mortars cured at elevated temperature - Part I: Expansive behaviour. Cem Concr Res 2003; 33: 807-814.

[23] Young JF. Humidity Control in the Laboratory using Salt Solutions - A Review. J Appl Chem 1967; 17: 241-247.

[24] O'Brien FEM. The Control of Humidity by Saturated Salt Solutions. J Scient Instrum 1948; 25: 73-76.

[25] NF P18-459, French norm - Concrete - Test for hardened concrete - Porosity and density test, 2010.

[26] Kollek JJ. The determination of the permeability of concrete to oxygen by the Cembureau method - a recommendation. Mater Struct 1989; 22: 225-230.

[27] AFREM, groupe durabilité des bétons «mode opératoire recommandé, essai de perméabilité au gaz du béton durci », compte rendu des journées techniques AFPC-AFREM, durabilité des bétons, « méthodes recommandées pour la mesure des grandeurs associées à la durabilité », Toulouse, France, 11-12 décembre, 1997, pp. 125-134. 
[28] Al Shamaa M, Lavaud S, Divet L, Nahas G, Torrenti JM., Coupling between mechanical and transfer properties and expansion due to DEF in a concrete of a nuclear power plant. Nucl. Eng. Des. 2014, 266: 70-77.

[29] Roubin E, Al Shamaa M, Colliat JB, Pavoine A, Divet L, Torrenti JM, Nahas G. A nonlinear meso-macro approach to modelling delayed ettringite formation and concrete degradation, Mater Struct 2013.

[30] Pavoine A., Brunetaud X., Divet L., The impact of cement parameters on Delayed Ettringite Formation, Cement and Concrete Composites, Volume 34, Issue 4, April 2012, Pages 521-528

[31] Brunetaud X., Linder R., Divet L., Duragrin D., Damidot D., Effect of curing conditions and concrete mix design on the expansion generated by delayed ettringite formation, Materials and Structures (2007) 40:567-578

[32] Brunetaud X. Etude de l'influence de différents paramètres et de leurs interactions sur la cinétique et l'amplitude de la réaction sulfatique interne au béton [PhD thesis]. Paris: Ecole Centrale de Paris; 2005. p. 265. 


\begin{tabular}{ll}
\hline Material & $\mathrm{Kg} / \mathrm{m}^{3}$ \\
\hline Cement CEM I 52.5 N & 400 \\
Sand 0/0.315 mm & 130 \\
Sand 0.315/1 mm & 130 \\
Sand $1 / 4 \mathrm{~mm}$ & 450 \\
Aggregate $4 / 8 \mathrm{~mm}$ & 210 \\
Aggregate $8 / 12.5 \mathrm{~mm}$ & 570 \\
Aggregate $12.5 / 20 \mathrm{~mm}$ & 310 \\
Water & 190 \\
\hline
\end{tabular}

Table 1. Concrete composition 


\begin{tabular}{lc}
\hline CEM I 52.5 N & Wt.\% \\
\hline $\mathrm{SiO}_{2}$ & 19.19 \\
$\mathrm{Al}_{2} \mathrm{O}_{3}$ & 5.03 \\
$\mathrm{Fe}_{2} \mathrm{O}_{3}$ & 2.06 \\
$\mathrm{TiO}_{2}$ & 0.31 \\
$\mathrm{MnO}$ & 0.04 \\
$\mathrm{CaO}$ & 62.68 \\
$\mathrm{MgO}$ & 0.92 \\
$\mathrm{SO}_{3}$ & 3.39 \\
$\mathrm{~K}_{2} \mathrm{O}$ & 1.03 \\
$\mathrm{Na}_{2} \mathrm{O}$ & 0.12 \\
$\mathrm{P}_{2} \mathrm{O}_{5}$ & 0.25 \\
$\mathrm{Na}_{2} \mathrm{O}_{\text {eq }}$ & 0.77 \\
$\mathrm{~S}^{2-}$ & 0.03 \\
$\mathrm{Cl}^{2-}$ & 0.02 \\
\hline
\end{tabular}

Table 2. Chemical composition of the Portland cement 


\begin{tabular}{lc}
\hline CEM I 52.5 N & Wt.\% \\
\hline $\mathrm{C}_{3} \mathrm{~S}$ & 67.4 \\
$\mathrm{C}_{2} \mathrm{~S}$ & 11.3 \\
$\mathrm{C}_{3} \mathrm{~A}$ & 10.7 \\
$\mathrm{C}_{4} \mathrm{AF}$ & 7.3 \\
\hline
\end{tabular}

Table 3. Mineralogical composition of the Portland cement 


\begin{tabular}{lllll}
\hline Salt & $\left(\mathrm{NH}_{4}\right)_{2} \mathrm{SO}_{4}$ & $\mathrm{KCl}$ & $\mathrm{BaCl}_{2}$ & $\mathrm{~K}_{2} \mathrm{SO}_{4}$ \\
\hline $\begin{array}{l}\text { Reliable temperature range } \\
\left({ }^{\circ} \mathrm{C}\right),(\text { Young) }\end{array}$ & $25-50$ & $5-40$ & $5-60$ & $15-60$ \\
$\mathrm{dRH} / \mathrm{dT}\left(\% /{ }^{\circ} \mathrm{C}\right)$ (Young) & -0.07 & -0.16 & -0.08 & -0.05 \\
$\mathrm{RH}$ à $25^{\circ} \mathrm{C}($ Young) & 80.2 & 84.2 & 90.3 & 97 \\
$\mathrm{RH}$ à $25^{\circ} \mathrm{C}\left(\mathrm{O}^{\prime}\right.$ Brien) & $81-89$ & $84-89$ & $88-93$ & 100 \\
\hline
\end{tabular}

Table 4. Salts used to obtain desired relative humidity and its dependence with temperature 


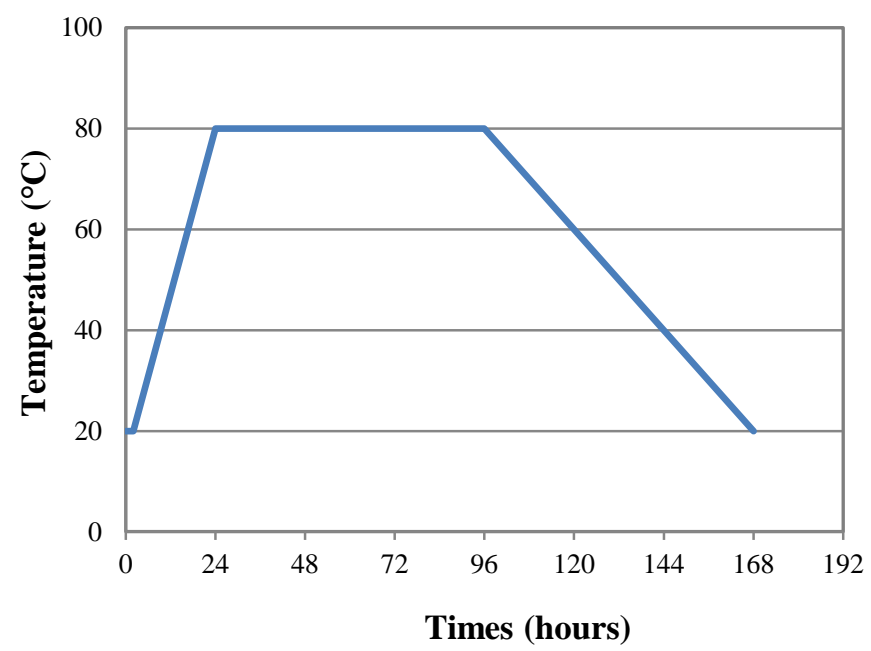

Figure 1. Temperature evolution during the heat treatment imposed on concrete specimens 


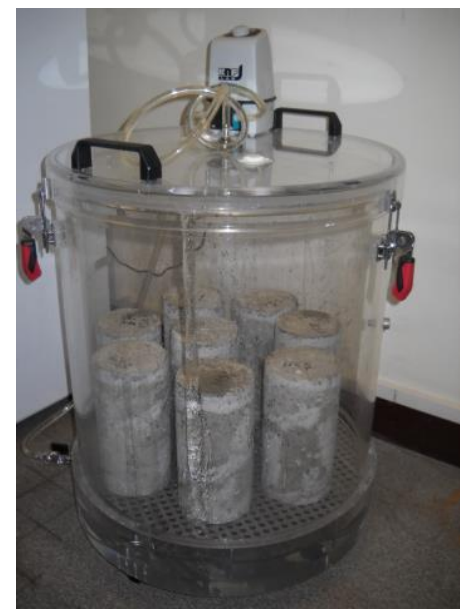

Figure 2. Storage container at $100 \% \mathrm{RH}$ 


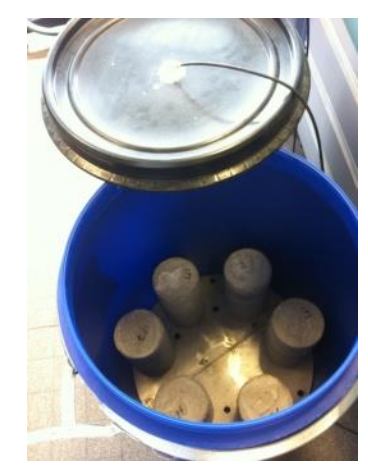

Figure 3. Top view of storage container at $91 \%<\mathrm{RH}<98 \%$ 


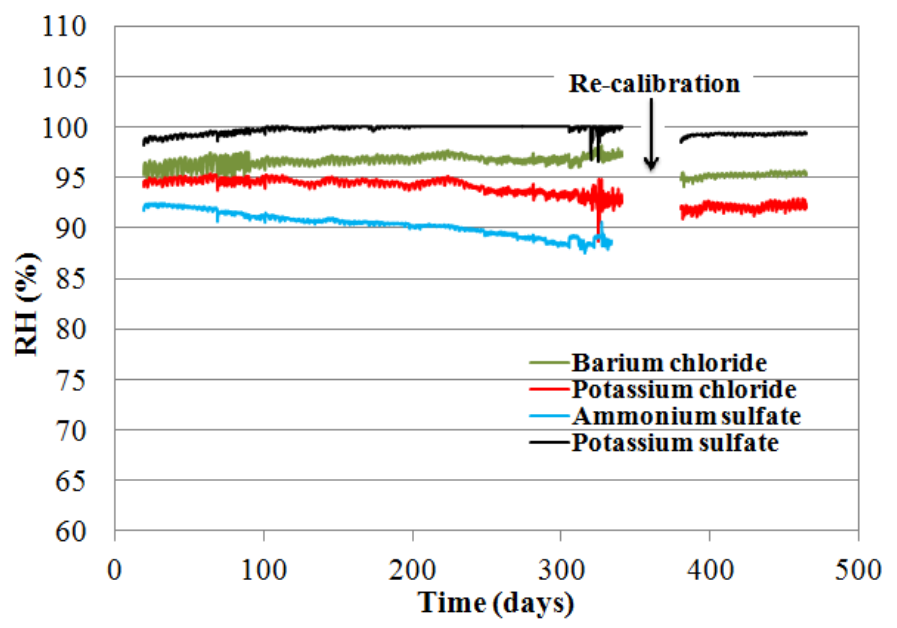

Figure 4. Recorded measurements of RH in the storage containers 


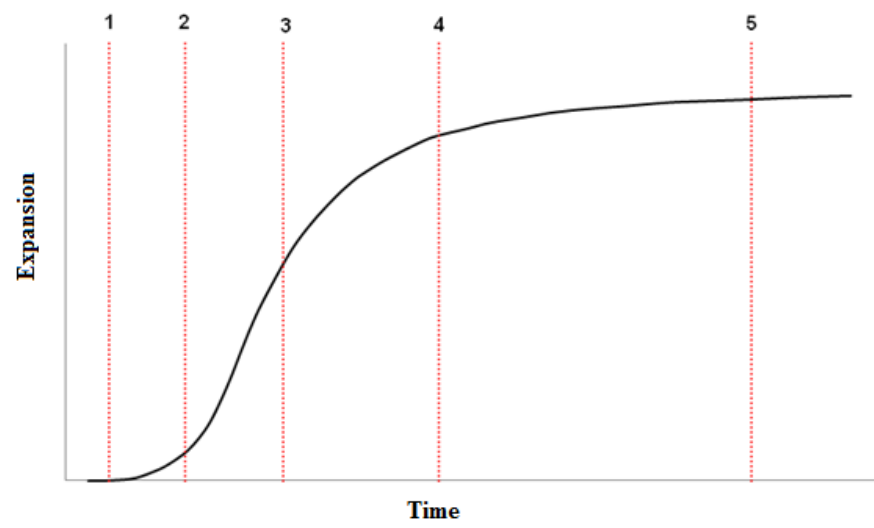

Figure 5. Dates of measurements of porosity and gas permeability compared to the evolution of the expansion for concretes Im and HR100 


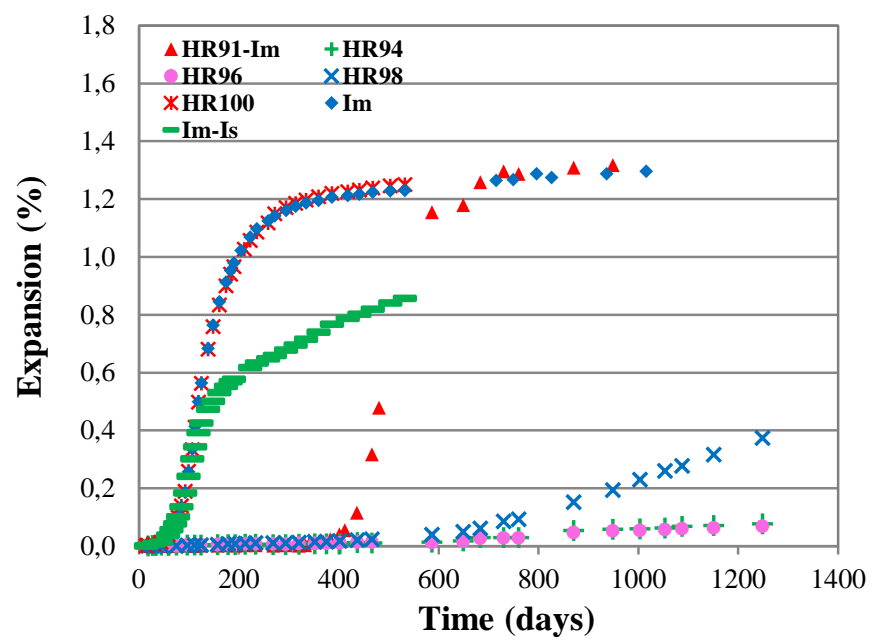

Figure 6. Expansions of all concrete specimens 


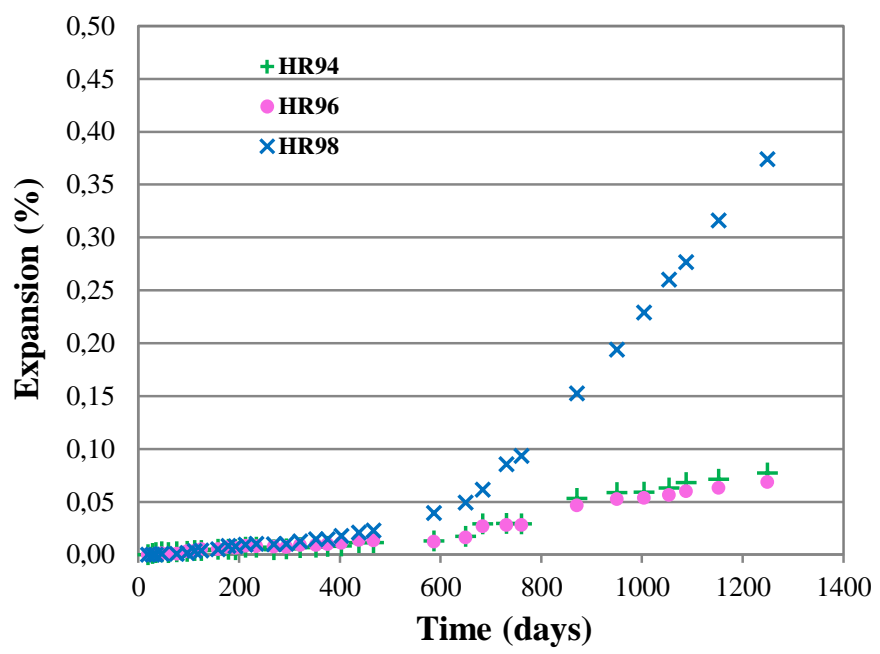

Figure 7. Expansions of concretes HR94, HR96 and HR98 


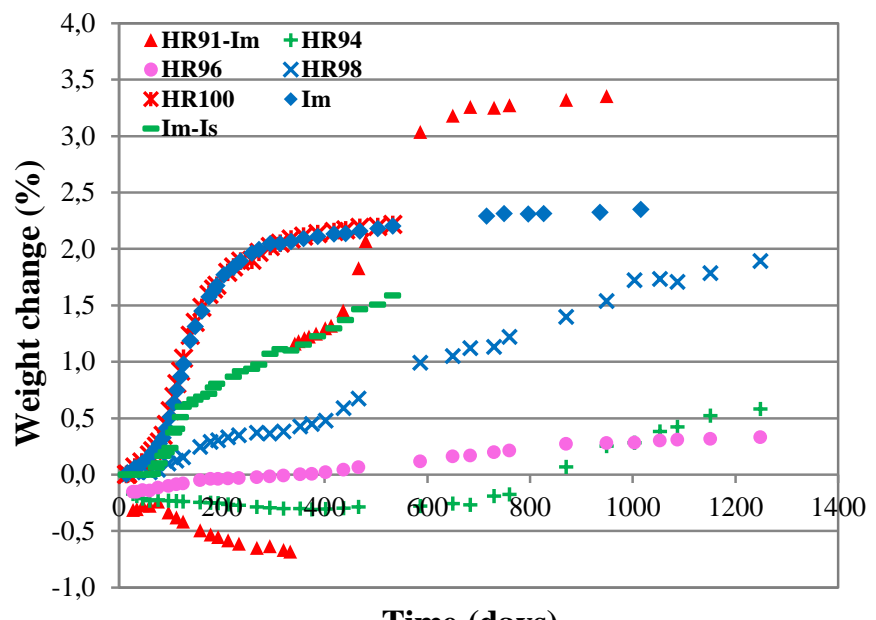

Time (days)

Figure 8. Weight changes of all concrete specimens 


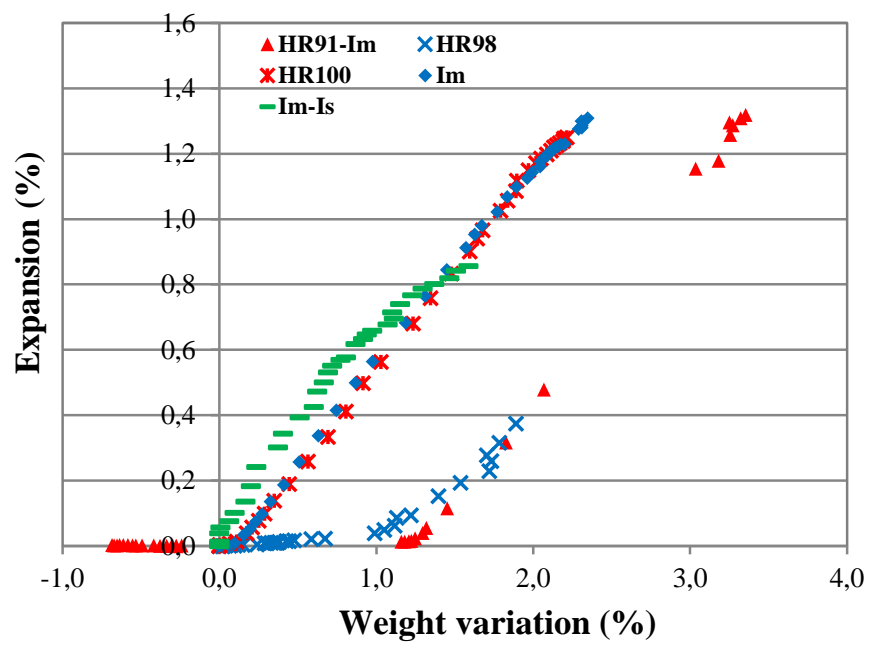

Figure 9. Expansion versus weight variation for concretes Im, HR100, HR98, Im-Is and HR91-Im 


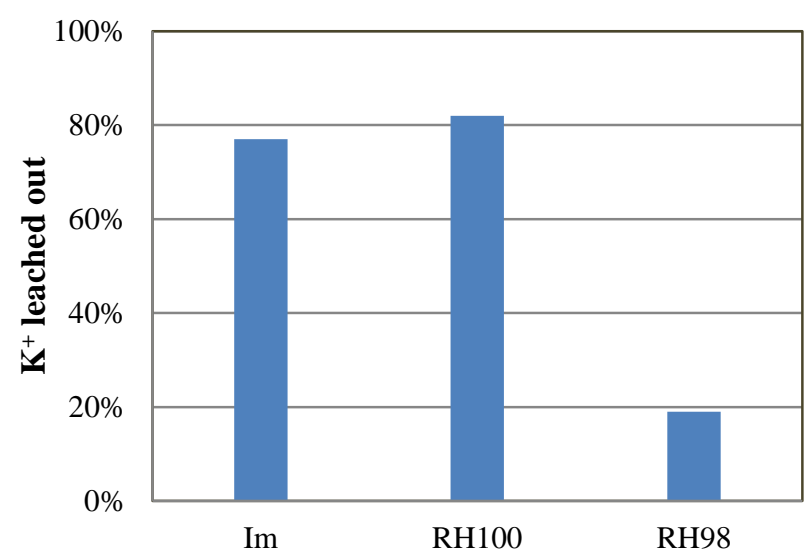

Figure 10. Comparison of $\mathrm{K}^{+}$leached out from the concretes RH100 and Im at 590 days and from concrete RH98 at 520 days (Wt.\%) 
(a)

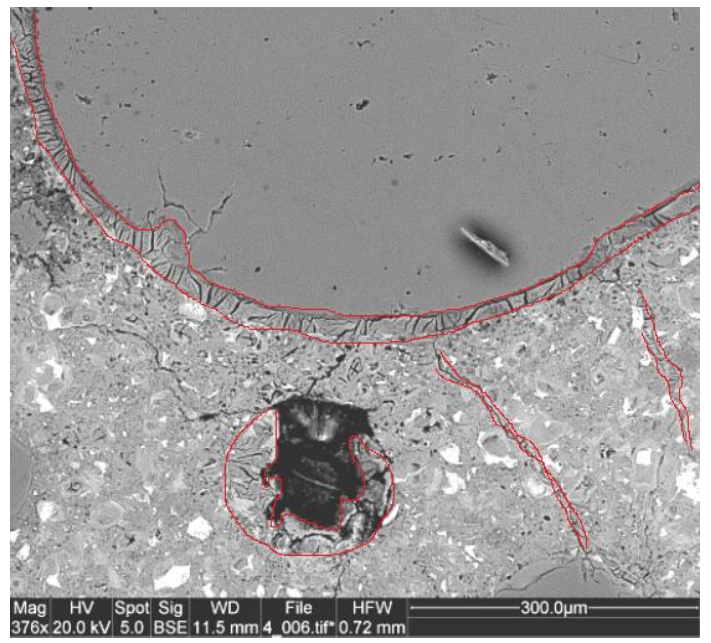

(b)

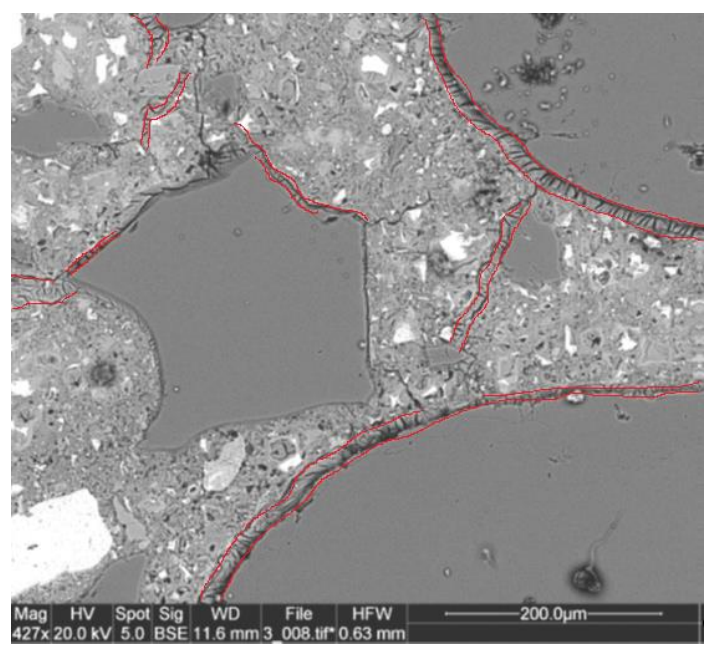

Figure 11. BEI of concretes Im (a) and RH100 (b) at 460 days. Ettringite is visible at the interface between paste and aggregates and within the cracks. 
(a)

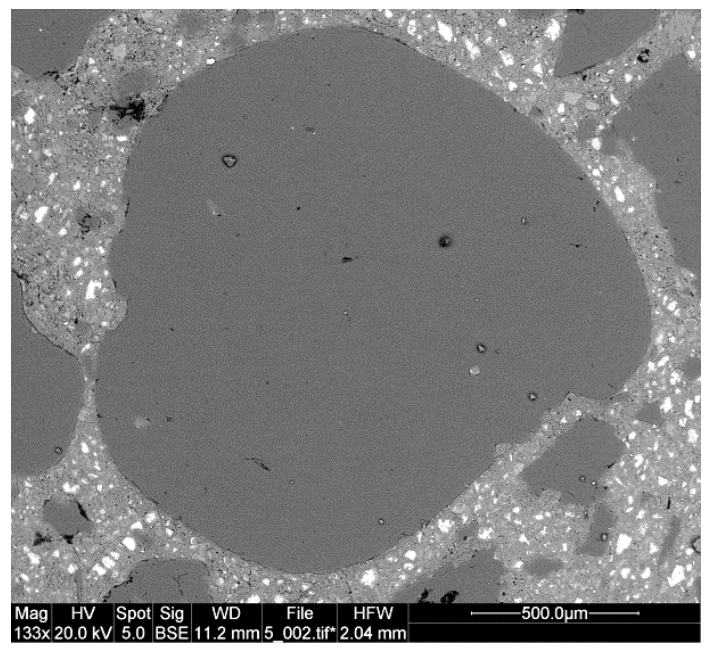

(b)

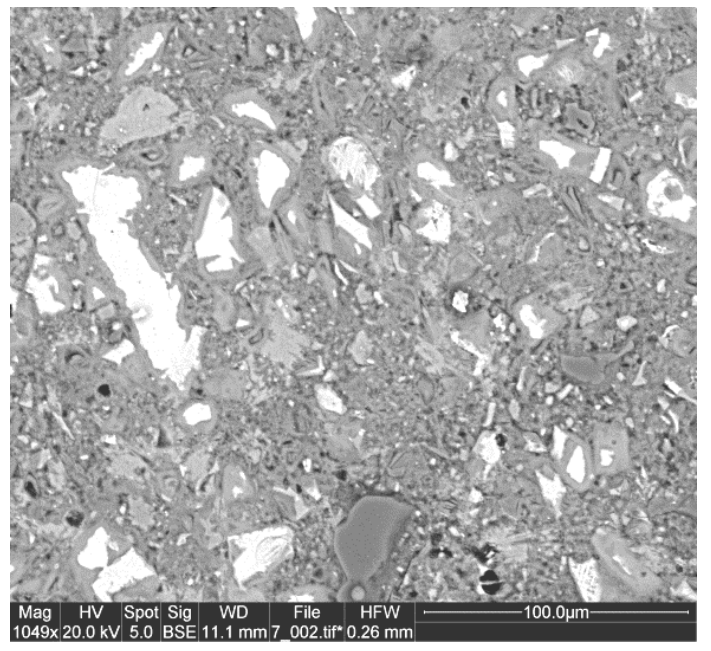

(c)

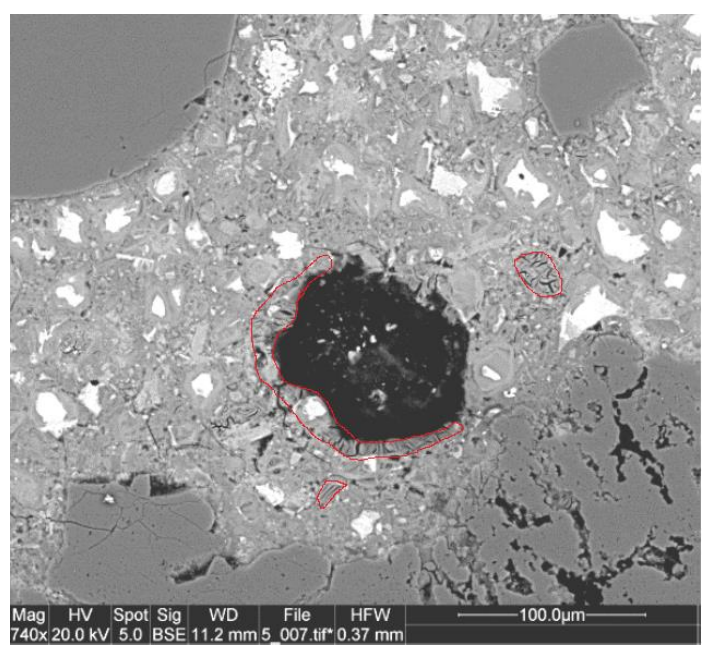


Figure 12. BEI of concretes RH94 (a), RH96 (b) and RH98 (c) at 400 days. Ettringite is only visible in the case of the RH98 specimen. 


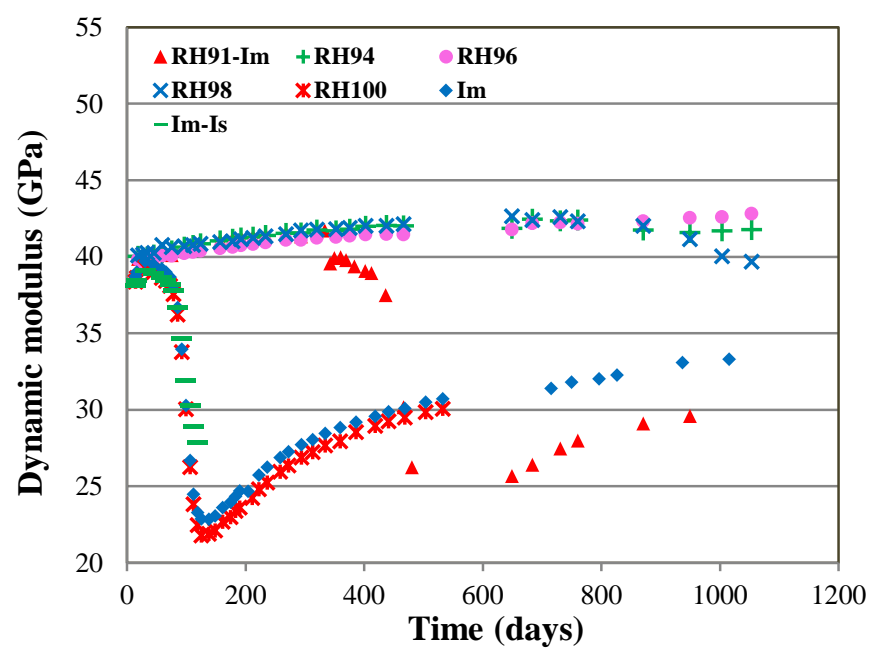

Figure 13. Dynamic modulus of elasticity versus time for all concrete specimens 


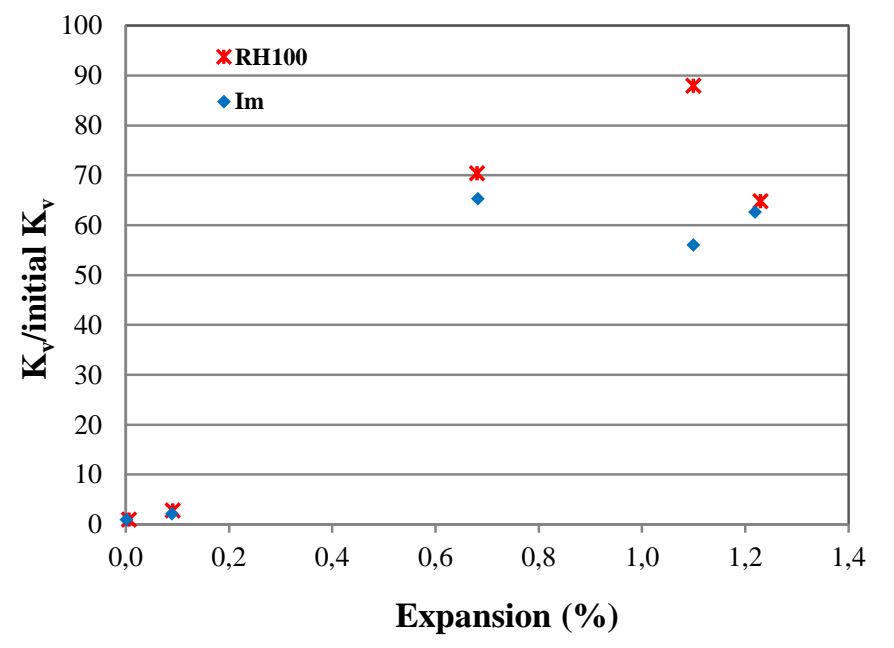

Figure 14. Variation of intrinsic permeability under expansion for concretes Im and RH100 


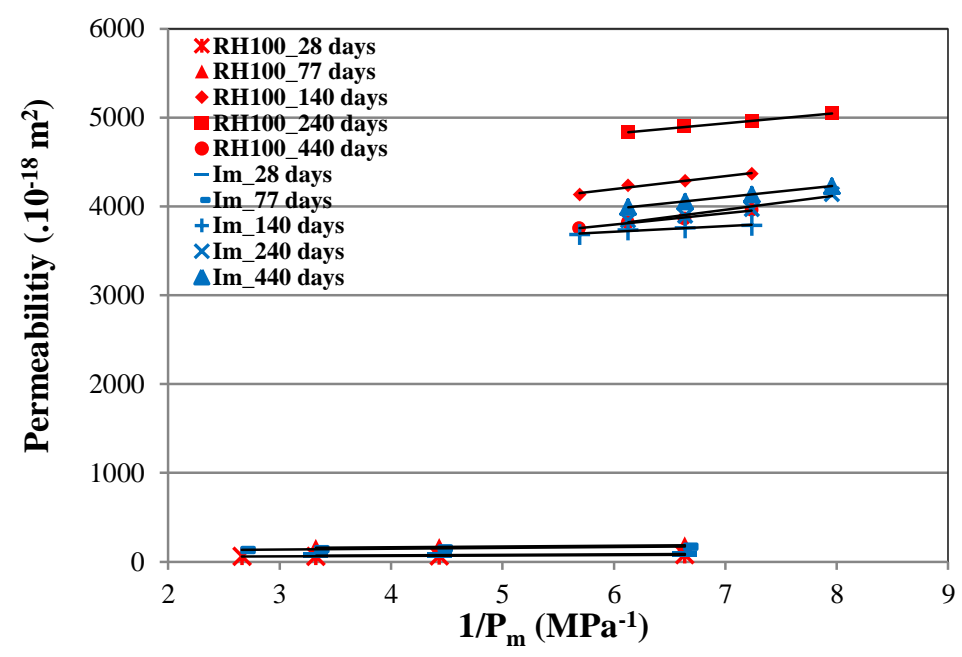

Figure 15. Effect of the mean gas pressure on the apparent

permeability for concretes Im and RH100 


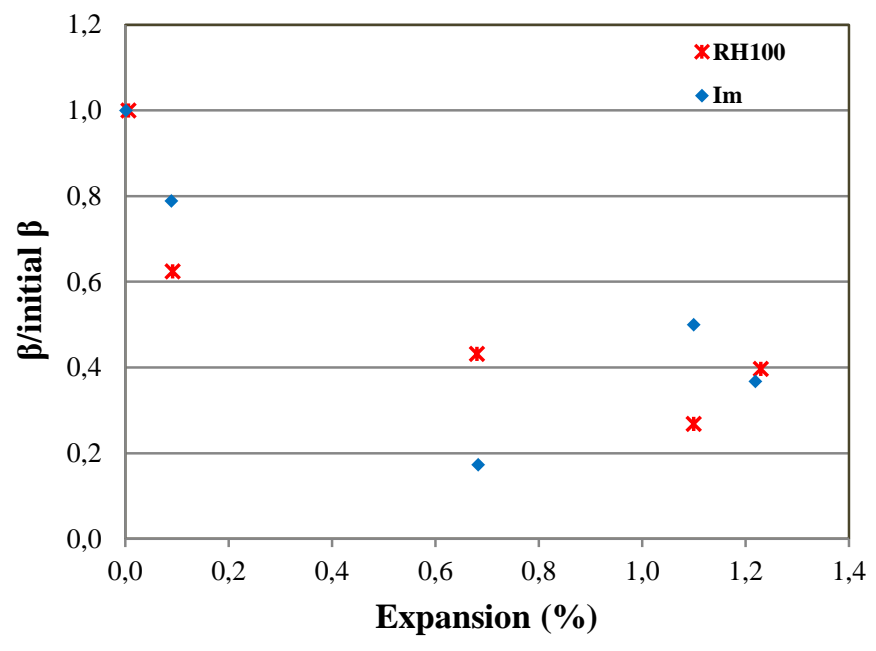

Figure 16. Variation of Klinkenberg coefficient under expansion for concretes Im and RH100 


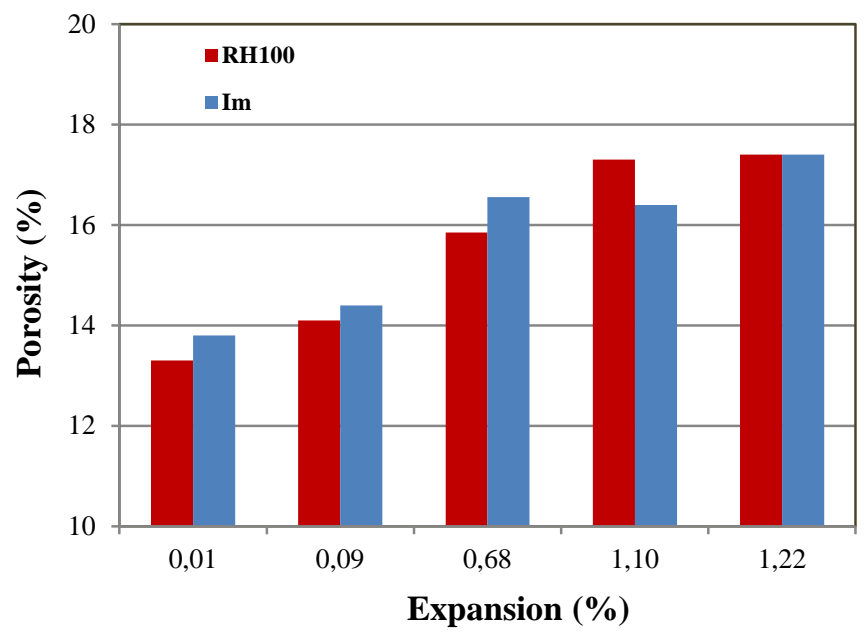

Figure 17. Effect of expansion on the porosity of concretes Im and RH100 


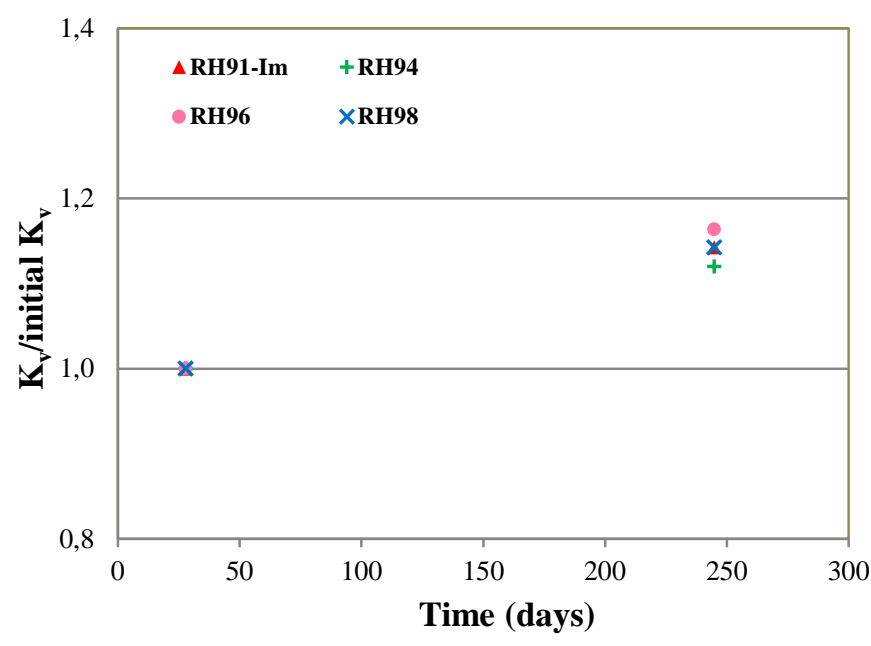

Figure 18. Variation of intrinsic permeability with time for concretes stored at $98 \% \mathrm{RH}$ and below 


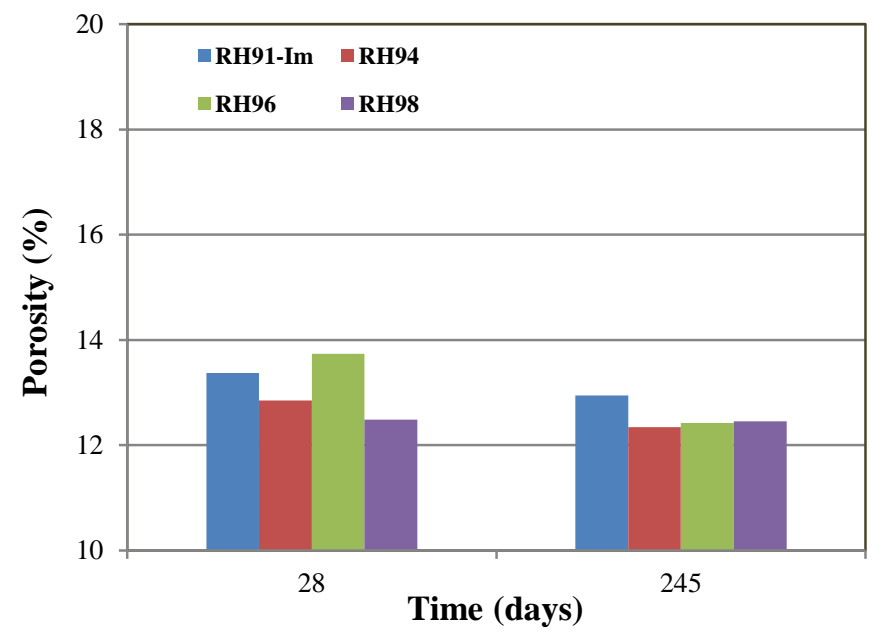

Figure 19. Porosity of concretes stored at $98 \% \mathrm{RH}$ and below 
(a)

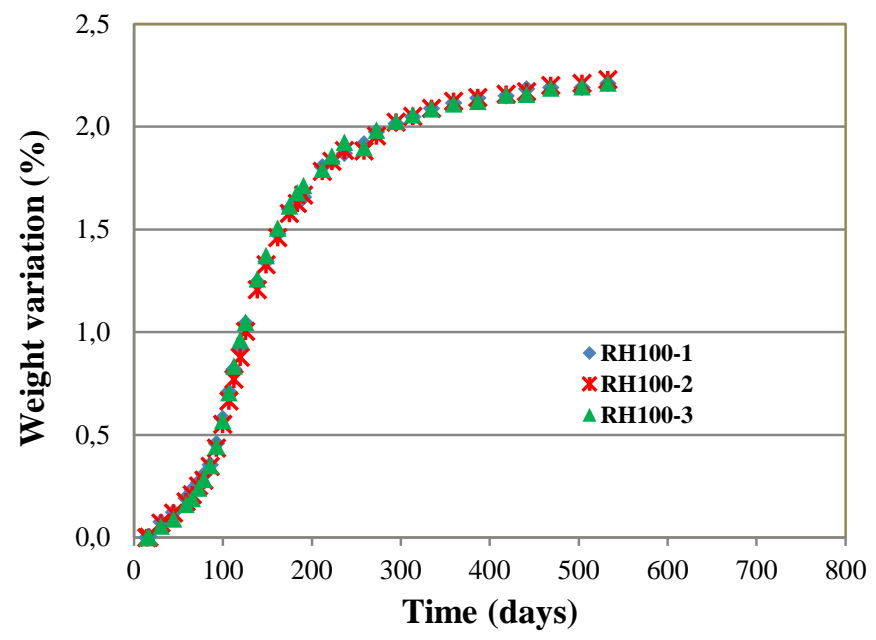

(b)

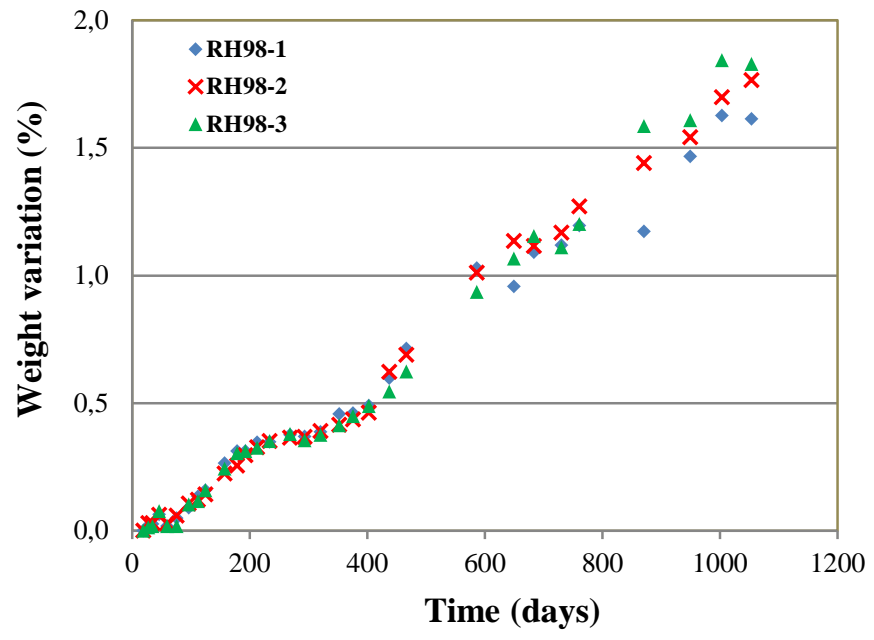

(c)

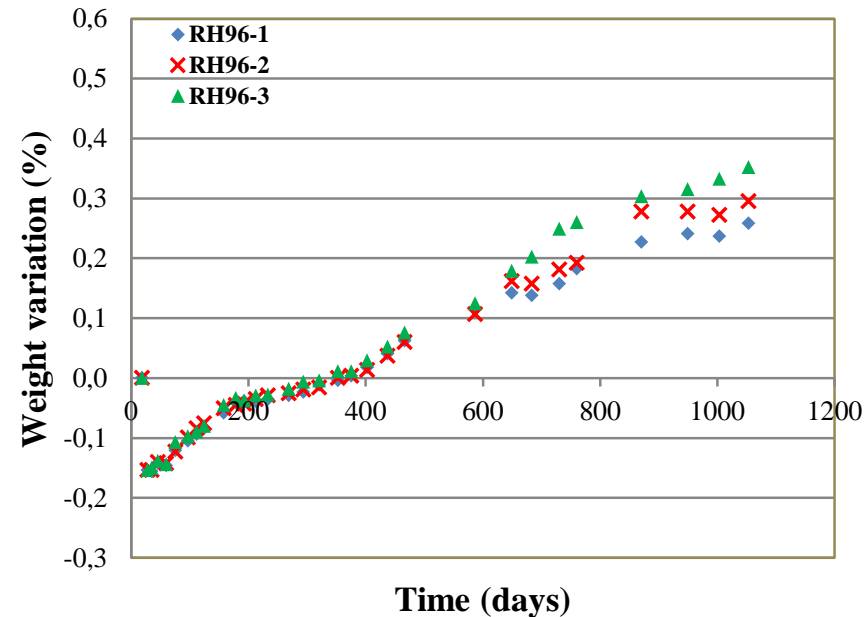

Figure 20: Individual concretes data showing uniform rate of weight variations for concretes RH100 (a), RH98 (b) and RH96 (c) 